\title{
Sex hormones and gene expression signatures in peripheral blood from postmenopausal women - the NOWAC postgenome study
}

\author{
Marit Waaseth" ${ }^{1 *}$ Karina S Olsen ${ }^{1}$, Charlotta Rylander ${ }^{1,2}$, Eiliv Lund ${ }^{1}$ and Vanessa Dumeaux
}

\begin{abstract}
Background: Postmenopausal hormone therapy $(\mathrm{HT})$ influences endogenous hormone concentrations and increases the risk of breast cancer. Gene expression profiling may reveal the mechanisms behind this relationship. Our objective was to explore potential associations between sex hormones and gene expression in whole blood from a population-based, random sample of postmenopausal women

Methods: Gene expression, as measured by the Applied Biosystems microarray platform, was compared between hormone therapy $(\mathrm{HT})$ users and non-users and between high and low hormone plasma concentrations using both gene-wise analysis and gene set analysis. Gene sets found to be associated with HT use were further analysed for enrichment in functional clusters and network predictions. The gene expression matrix included 285 samples and 16185 probes and was adjusted for significant technical variables.

Results: Gene-wise analysis revealed several genes significantly associated with different types of HT use. The functional cluster analyses provided limited information on these genes. Gene set analysis revealed 22 gene sets that were enriched between high and low estradiol concentration (HT-users excluded). Among these were seven oestrogen related gene sets, including our gene list associated with systemic estradiol use, which thereby represents a novel oestrogen signature. Seven gene sets were related to immune response. Among the 15 gene sets enriched for progesterone, 11 overlapped with estradiol. No significant gene expression patterns were found for testosterone, follicle stimulating hormone (FSH) or sex hormone binding globulin (SHBG).
\end{abstract}

Conclusions: Distinct gene expression patterns associated with sex hormones are detectable in a random group of postmenopausal women, as demonstrated by the finding of a novel oestrogen signature.

\section{Background}

Previous reports have shown that there is an association between plasma/serum concentrations of endogenous sex hormones and the risk of breast cancer among postmenopausal women [1-3]. The Women's Health Initiative [4] and large observational studies $[5,6]$ have also shown that use of postmenopausal hormone therapy (HT) increases the risk of breast cancer. Exogenous hormones have an influence on endogenous hormone concentrations. Systemically administered HT containing estradiol $\left(E_{2}\right)$ suppresses plasma concentrations of follicle stimulating hormone (FSH) and increases $E_{2}$ and sex

\footnotetext{
* Correspondence: marit.waaseth@uit.no

'Department of Community Medicine, University of Troms $\varnothing$, Troms $\varnothing$, Norway Full list of author information is available at the end of the article
}

hormone binding globulin (SHBG) concentrations [7-9]. Tibolone use suppresses both FSH and SHBG concentrations in blood and increases free testosterone $(\mathrm{T})$ because of lower SHBG levels [10,11].

Blood is a fluid connective tissue that interacts with all other human tissues, and peripheral blood cells have been found to reflect system wide biology [12,13]. Being easily accessible, peripheral blood can be an excellent surrogate tissue for exploring the effects of environmental exposure on gene expression in large epidemiological studies. Microarray analysis of the blood transcriptome may shed light on the etiologic pathways connecting environmental exposure and disease [13], and gene expression signatures are hypothesised to become important diagnostic tools or prognostic biomarkers [14]. 
Except for previous research in the Norwegian Women and Cancer study (NOWAC) $[15,16]$, population-based studies on whole blood gene expression in postmenopausal women are scarce. However, some research on blood cells or tissue biopsies has reported gene expression patterns associated with HT and other menopause-related variables [17-22].

The population-based NOWAC postgenome cohort study provides opportunities for conducting nested casecontrol studies using gene expression analyses of whole blood [23]. A first step would be to assess the predisease impact of known risk factors for female cancer (e.g., circulating sex hormone levels, or HT) on gene expression.

The objective of this study was to explore potential associations between different levels of endogenous and exogenous sex hormones and gene expression in whole blood from a random sample of postmenopausal women.

\section{Methods}

\section{Subjects}

An extensive description of NOWAC has been published elsewhere [24]. Briefly, NOWAC is a national, population-based cohort study among women 30-70 years old, with questionnaire data on lifestyle and health collected at 4-6 year intervals.

The participants were randomly drawn from the Norwegian Central Population Register. By June 2007, approximately 172000 women were enrolled in NOWAC overall. The study complied with the Declaration of Helsinki and all participants gave written informed consent. The study was approved by the Regional Committee for Medical and Health Research Ethics and the Norwegian Data Inspectorate. The NOWAC postgenome cohort comprises questionnaire data and blood samples collected during the 2003-2006 period from approximately 50000 women born from 1943 to 1957 [23]. See Additional file 1 for a copy of the questionnaire (translated). For the present analyses, we used a randomly drawn group of 445 third-time participants from the NOWAC postgenome cohort who donated a blood sample in 2005 (Figure 1). The overall response rate was $74 \%$. The exclusion of subjects with incompletely filled blood collection tubes, $>3$ days from blood collection to frozen sample or pre-/perimenopausal status, left 328 PAXgene (PreAnalytiX GmbH, Hembrechtikon, Switzerland) whole blood samples for RNA extraction.

\section{Endogenous hormones measurements}

Plasma concentrations of estradiol $\left(E_{2}\right)$, progesterone $\left(\mathrm{P}_{4}\right)$, testosterone $(\mathrm{T})$, follicle stimulating hormone (FSH) and sex hormone binding globulin (SHBG) were

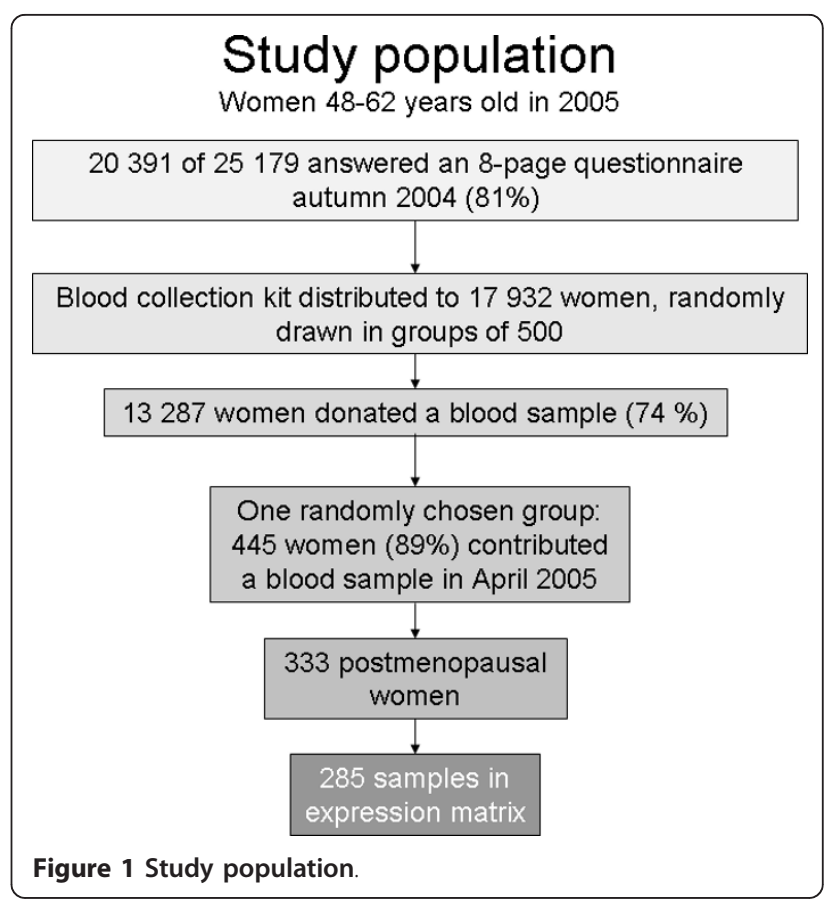

measured by immunometry, as described in a previous report[7]. For convenience, SHBG is referred to as a hormone throughout this text.

\section{RNA isolation}

Total RNA was isolated using the PAXgene Blood RNA Isolation Kit, according to the manufacturer's protocol (PreAnalytiX GmbH, Hembrechtikon, Switzerland). The RNA quantity and purity were assessed by the NanoDrop ND-1000 spectrophotometer (ThermoFisher Scientific, Wilmington, Delaware, USA). The absorbance ratio for $260 \mathrm{~nm}$ and $280 \mathrm{~nm}$ (A260/A280) was between 1.93 and 2.1 for all of the samples included for further analysis. The Experion automated electrophoresis system (BioRad, Hercules, CA, USA) and the RNA StdSens Analysis Kit were used to evaluate the RNA integrity of a randomised $32 \%$ of the samples, according to the manufacturer's protocol. Thirty-nine samples were excluded because of insufficient purity or yield.

\section{Microarray-based profiling and image analysis}

The samples were analysed using the Applied Biosystems expression array system (Foster City, LA, USA). From each sample, 500 ng of total RNA was amplified using the NanoAmp RT-IVT labelling kit for one round of amplification (Applied Biosystems), in accordance with the manufacturer's protocol. The quantity and purity of the cRNA was measured using the NanoDrop ND-1000. Digoxigenin (DIG)-labelled cRNA, $10 \mu \mathrm{g}$ per sample, was fragmented and hybridised to the Applied Biosystems Human Genome Survey Microarray V2.0, in 
accordance with the Chemiluminescence Detection Kit Protocol. Each microarray chip contained 277 control probes and 32878 probes representing 29098 genes. The Applied Biosystems Expression System software was used to extract signal intensities, signal to noise ratios $(\mathrm{S} / \mathrm{N})$ and flagging values from the microarray images.

\section{Data analysis}

The data were analysed using $\mathrm{R}$ version 2.8 .1 (http:// cran.r-project.org) and tools from the Bioconductor project (http://www.bioconductor.org). For genes with a flagging value $>8191$, the expression intensity was set to missing. Three samples where less than $40 \%$ of the probes showed $\mathrm{S} / \mathrm{N} \geq 3$ were excluded. Probes with $\mathrm{S} / \mathrm{N} \geq 3$ in less than $50 \%$ of the samples were filtered out. We subsequently performed log transformation, quantile normalisation, and imputation of missing values using the $\mathrm{k}$-nearest neighbourhood method $(k=10)$. The gene expression values were adjusted for significant technical variables (i.e., array lot number, RNA extraction date and time between blood collection and storage) using gene-wise mixed linear modelling [25]. One sample was excluded as an outlier because of high plasma $\mathrm{E}_{2}$ and $\mathrm{P}_{4}$ concentrations, which was probably due to misclassification of menopausal status. The final expression matrix comprised 285 samples and 16185 probes. The microarray data have been deposited at Gene Expression Omnibus (GEO; http://www.ncbi.nlm.nih.gov/geo), accession number GSE15289.

The effect of different HT regimens and hormone concentrations on the expression of individual genes was tested using a linear model, limma[26], adjusted for multiple testing using the false discovery rate (FDR) [27].

The gene sets defined from the limma analyses, which were extracted from the literature or found in publicly available web applications, such as KEGG (Kyoto Encyclopaedia of Genes and Genomes) [28] or AmiGO [29], were tested for differential expression between groups with high and low hormone concentration using globaltest [30]. The table in Additional File 2 lists all the 56 gene sets included in the analysis. The gene sets fulfilling the criteria $\mathrm{p}<0.05$, FDR $<0.25$, and comparative $\mathrm{p}$ $<0.20$ were defined as differentially expressed. The comparative $\mathrm{p}$-value denotes the percentage of random gene sets of the same size that would have a larger test statistic than the gene set in question. The same method was used to test for gene set enrichment between the different categories of HT use versus non-use. Core genes for each significant gene set were defined as the genes with the highest influence on the differences seen (with a cut-off of z.score >1.5).
The analyses were adjusted for the variables that were significantly different between the groups in question (i.e., age and/or body mass index (BMI)).

Information on specific genes was found at GeneCards $^{\circledR}$ (http://www.genecards.org) [31]. Some genes were not assigned an approved gene symbol and are referred to as "unassigned" or by the Celera Gene ID, if one was provided in the Applied Biosystems annotation.

The searches for gene networks and pathways were performed using DAVID (the Database for Annotation, Visualisation and Integrated Discovery) [32] and HEFalMp (Human Experimental/Functional Mapper) [33].

Endogenous hormones were analysed as dichotomised variables: high (fourth quartile) versus low (first quartile) of hormone concentration, with cut-offs defined among the non-users of medication. Users of HT and thyroxine $\left(\mathrm{T}_{4}\right)$ were excluded from these analyses.

Exogenous hormones were categorised as use of systemic $E_{2}$ or $E_{2}$ and progestogen (P) (tablets or patches), systemic $\mathrm{E}_{2}$ alone (patches), tibolone or total HT. Although not defined as postmenopausal $\mathrm{HT}, \mathrm{T}_{4}$ use was also defined as a category. The different types of exogenous hormones were compared to non-use. Users of other medication (e.g., blood pressure lowering agents, antibiotics, antihistamines) were excluded from these analyses.

\section{Results}

HT use

Among the 285 women, 182 were medication users (52 used HT and 159 used other medication). Table 1 shows the participant characteristics for the study sample.

Table 2 shows the results from the limma analysis, comparing different categories of HT with non-users (users of other medication excluded). Five genes were significantly associated with HT use, and nine genes with FDR $<0.28$. The list of differentially expressed genes associated with use of " $E_{2}$ or $E_{2} / P$ systemic" treatment was the longest $(n=33)$. The overlap between the gene sets from the three HT categories that contain estradiol is shown in Figure 2. Tibolone and $\mathrm{T}_{4}$ use resulted in 400 and 8 differentially expressed genes, respectively. Because of the limited number of tiboloneonly users $(\mathrm{n}=2)$, a complementary analysis comprising all tibolone users was conducted. With an FDR cut-off at 0.50 , we found 58 genes; no genes had FDR $<0.41$. Among these 58 genes, 21 were significantly associated with the tibolone-only users.

Using functional annotation clustering in DAVID, the " $E_{2}$ or $E_{2} / P$ systemic" gene set was enriched (enrichment score 1.67) in one cluster that included six general cellular component GO terms. Among them was 


\begin{tabular}{lr}
\hline Age, years & $55.7(3.6)$ \\
BMI, $\mathrm{kg} / \mathrm{m}^{2}$ & $25.6(4.3)$ \\
& \\
Sex hormone concentration & \\
& \\
Estradiol nmol/L & \\
Progesterone $\mathrm{nmol} / \mathrm{L}$ & $0.10(0.09)$ \\
Testosterone $\mathrm{nmol} / \mathrm{L}$ & $0.99(0.67)$ \\
FSH IU/L & $1.16(0.74)$ \\
SHBG nmol/L & $70.2(28.0)$ \\
Medication use & $47.6(21.8)$ \\
HT & $182(64 \%)$ \\
$\quad E_{2}$ and $E_{2} / \mathrm{P}$ systemic & $52(18 \%)$ \\
$\quad E_{2}$ systemic alone & $32(62 \%)$ \\
$\quad$ Tibolone & $9(17 \%)$ \\
$\quad$ Vaginal treatment & $10(19 \%)$ \\
Thyroxine & $9(17 \%)$ \\
Other medication & $20(7 \%)$ \\
No medication & $159(56 \%)$ \\
Number of medications used $(\mathrm{n}=182)$ & $98(34 \%)$ \\
1 medication & \\
2 medications & \\
>2 medications & $97(53 \%)$ \\
Current smoker & $62(34 \%)$ \\
Yes & $23(13 \%)$ \\
No & $209(73 \%)$ \\
$\quad$
\end{tabular}

"intracellular membrane bound organelle", which had the lowest FDR (0.17). The " $E_{2}$ alone" gene set and the $\mathrm{T}_{4}$ gene set revealed no enriched clusters. HEFalMp predicted a few gene networks for the tibolone gene set (Figure 3). The tibolone gene set revealed no significantly enriched annotation clusters in DAVID. However, one individual GO term, "alcohol metabolic process" which was based on four genes (ALDH2, PRDX1, PDIA and $\mathrm{PNPO}$ ), was significant $(\mathrm{FDR}=0.06)$.

\section{High and low hormone concentrations}

Comparing the high and low hormone concentrations using a gene-wise approach (limma, $\mathrm{HT}$ and $\mathrm{T}_{4}$ users excluded), two genes of unknown biological function (DGCR9 and $h C G 2018460$ ) were significantly differentially expressed between high and low levels of FSH. No genes were significant for any of the remaining hormones. However, we observed significant gene set enrichment between high and low concentrations of $E_{2}$ and $\mathrm{P}_{4}$ (the table in Additional file 3, with $\mathrm{HT}$ and $\mathrm{T}_{4}$ users excluded).

Out of the 22 gene sets significant for $E_{2}$, seven were oestrogen or HT related, including the " $E_{2}$ or $E_{2} / P$ systemic" gene set. Seven gene sets extracted from four publications were related to white blood cells and immune response, and the remaining eight (from five

Table 2 Number of genes differentially expressed between HT users and non-users (in the Limma analysis)

\begin{tabular}{lccc}
\hline HT type & Total sample $\mathbf{N}$ & Single users ${ }^{\mathbf{1}} \mathbf{N}$ & Number of genes FDR $<0.25$ \\
\hline HT all types & 52 & 23 & $5(9)^{2}$ \\
$\mathrm{E}_{2}$ or $\mathrm{E}_{2} / \mathrm{P}$ systemic & 32 & 15 & 33 \\
$\mathrm{E}_{2}$ systemic & 9 & 7 & 10 \\
Tibolone & 10 & 2 & 400 \\
Tibolone2 $^{3}$ & 10 & 10 & $0(58)^{3}$ \\
Thyroxine $_{\text {Non-users }}^{3}$ & 20 & 5 & 8 \\
\hline
\end{tabular}

\footnotetext{
1 Users of other medication excluded.
}

${ }^{2}$ FDR $<0.28,5$ genes with FDR $<0.25$.

${ }^{3}$ All tibolone users were included in the analysis; there were 58 genes with FDR $<0.50$. 


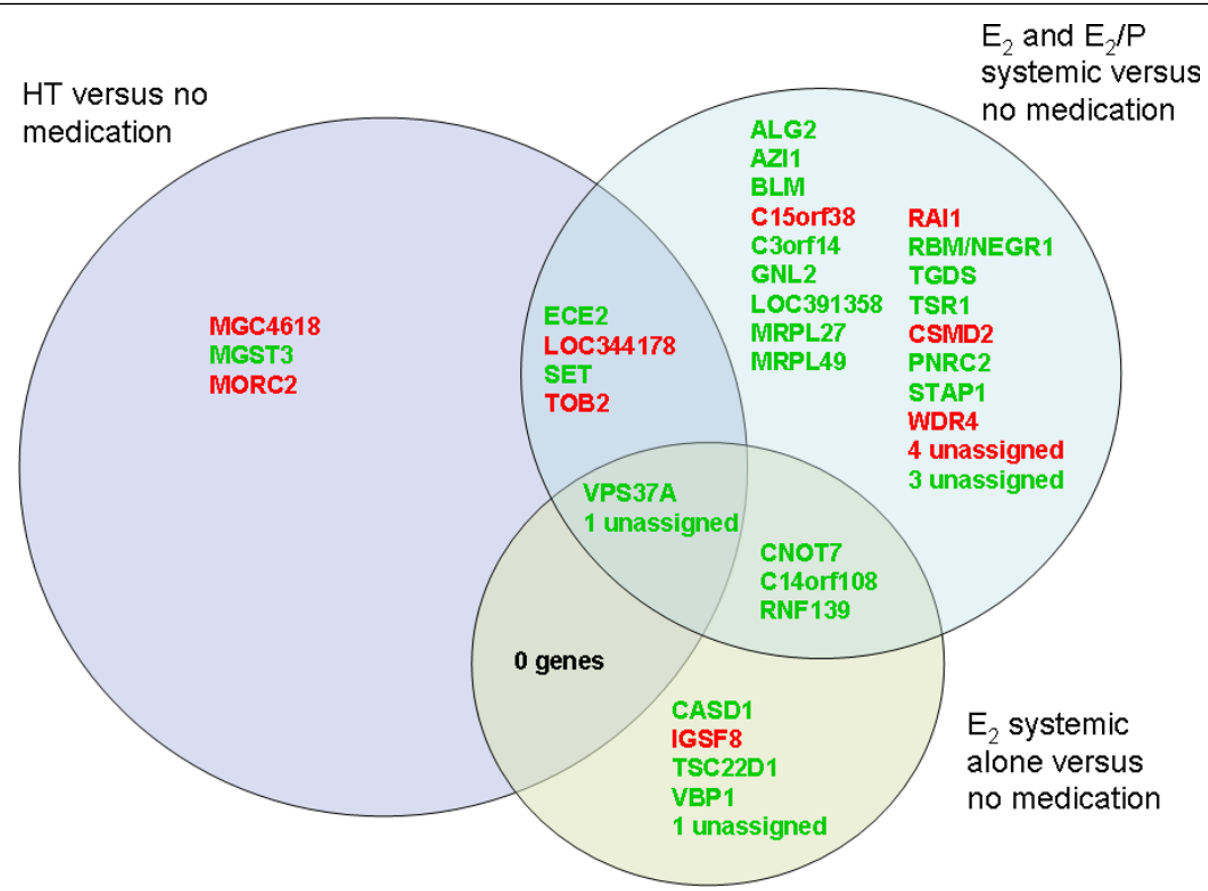

Figure $\mathbf{2}$ The three gene sets (circles) found when comparing different categories of HT users with non-users. The partly overlapping circles show which genes were significant for one, two or all three HT categories. All three categories include users of systemic $E_{2}$. Gene symbols in red denote genes up-regulated in users and gene symbols in green denote genes up-regulated in non-users. Among the 9 HT genes, LOC344178, SET, MGC4618 and MORC2 have FDR $<0.28$, the remaining 5 genes have FDR $<0.25$.

publications) were related to proto-oncogenes, exercise, age, consuming a carbohydrate/protein breakfast, transcription factors and drug metabolising enzymes. Among the 15 gene sets differentially expressed for $\mathrm{P}_{4}$, 11 were also significant for $E_{2}$, although with slight

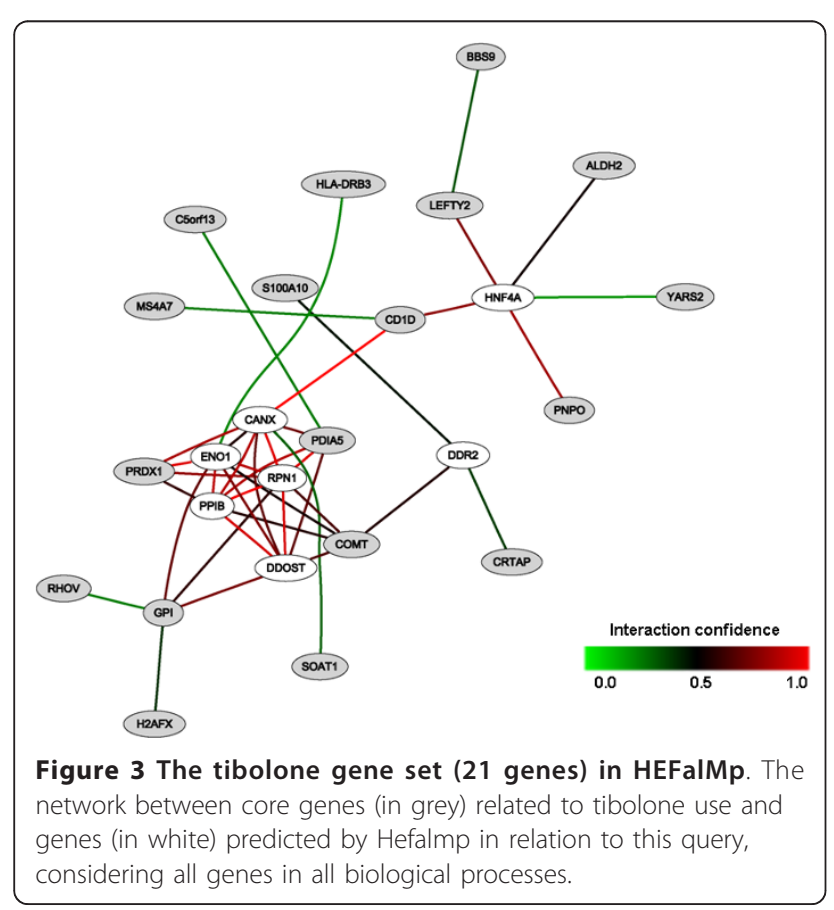

differences in the core genes. Among the 186 different core genes, 151 (81\%) were up-regulated in women with low $\mathrm{E}_{2} / \mathrm{P}_{4}$ concentrations. Among these, 71 (47\%) were present for $\mathrm{E}_{2}, 34(23 \%)$ were present for $\mathrm{P}_{4}$ and 45 (30\%) appeared on both lists. Among the 35 core genes up-regulated in women with high $\mathrm{E}_{2} / \mathrm{P}_{4}$ concentrations, $19(54 \%)$ genes were present for $E_{2}, 14(40 \%)$ were present for $\mathrm{P}_{4}$ and $2(6 \%)$ were on both lists. When investigating FSH, SHBG and T, no gene set fulfilled all three criteria for differential expression in the gene set analysis. Of note, the same analysis conducted without excluding HT and thyroxine users only marginally altered the ranking of the gene sets by p-value, but the p-values and FDRs increased slightly (data not shown).

Our " $E_{2}$ or $E_{2} / P$ systemic" gene set was only significant for $E_{2}$, and therefore it represents a novel oestrogen gene expression signature. Among the six core genes for the " $E_{2}$ or $E_{2} / P$ systemic" gene set (Figure 4), five had unknown function, while RAI1 may function as a transcription regulator. Comparing the direction of gene expression (up- or down-regulation) for the " $E_{2}$ or $E_{2} / P$ systemic" gene set between endogenous and exogenous $E_{2}$ (Figures 2 and 4), we found $61 \%$ concordance for all 33 probes and $80 \%$ concordance among the 10 most influential probes. The second most influential gene (C3orf14) was up-regulated in high $\mathrm{E}_{2}$ but down-regulated among users of systemic $E_{2}$ relative to non-users. Gene 


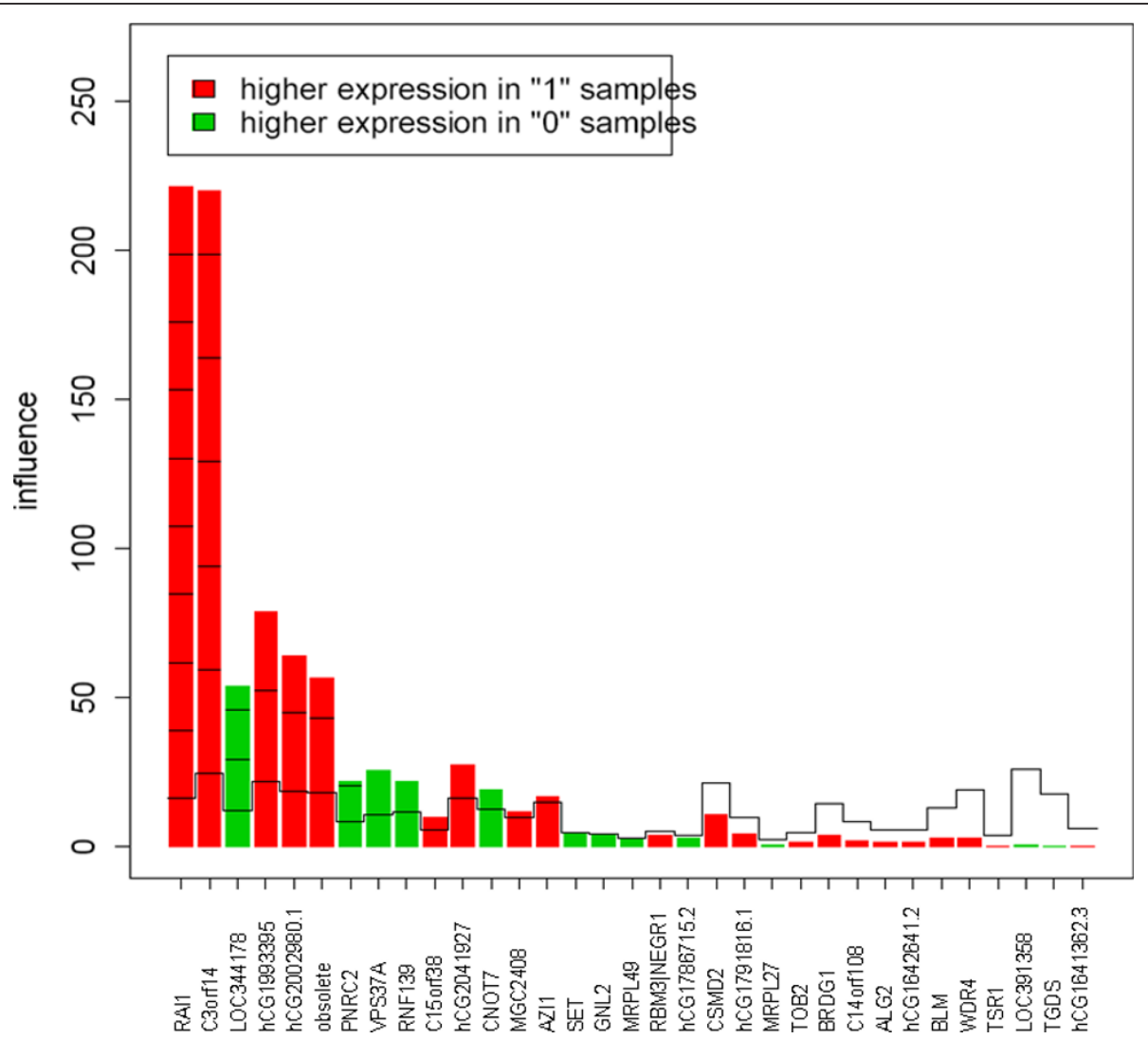

Figure 4 Gene plot of the " $E_{2}$ or $E_{2} / P$ systemic" gene set (33 genes) in relation to $E_{2}$ concentration ("0" = low, "1" = high). The reference line for each bar represents the expected height under the null hypothesis (i.e., that the gene is not associated with hormone concentrations). The marks indicate the number of standard deviations above the reference line.

number three (LOC344178) was down-regulated in high $E_{2}$ but up-regulated among users of systemic $E_{2}$. None of the five genes that overlapped between the " $E_{2}$ alone" and " $E_{2}$ or $E_{2} / P$ systemic" gene sets (Figure 2) were among the six core genes; they were ranked as numbers $8,9,12$ and 21 (Figure 4).

\section{Discussion}

This study confirms that a population based cohort study such as NOWAC provides the opportunity to use high throughput technology (e.g., microarray analysis) to explore biologic variation in gene expression related to both endogenous and exogenous sex hormones.

According to the gene-wise analysis, hormone concentrations did not show a profound influence on gene expression. This result is not surprising, given the low variability that is present in a study group representing the general postmenopausal population. Conversely, all categories of HT use produced differentially expressed genes when compared with non-users. This finding is attributable to the wider range of hormone concentrations between the groups in this analysis. Intake of exogenous $\mathrm{E}_{2}$, particularly by systemic administration, increases endogenous plasma $\mathrm{E}_{2}$ and suppresses plasma FSH toward premenopausal levels [7]. Apart from the direct hormonal effects, a probable cause is the supply of synthetic medical substances (e.g., tibolone, progestogens and their metabolites) to the blood. The overlap between the gene sets shown in Figure 2 was probably caused by the overlap of subjects; all of the women using systemic $E_{2}$ alone are included among the women using $\mathrm{E}_{2} \mathrm{P}$ systemic, who are again included among the HT-users. Also, these genes seem the most stable, as they remain significant even if the sample group composition is changed. The minimal information on gene function for the two $E_{2}$ gene sets in DAVID could be due to the nature of gene-wise analysis, which assumes that genes are expressed independently of each other.

The gene set enrichment analysis showed a fair amount of overlap between $\mathrm{P}_{4}$ and $\mathrm{E}_{2}$, a plausible result considering the positive correlation between the two hormones $(\mathrm{r}=0.43, \mathrm{p}<0.01)$. Among the 58 subjects present in both the $\mathrm{E}_{2}$ and the $\mathrm{P}_{4}$ analyses, 49 were concordantly in the low or high group for both hormones. Hence, it may be difficult to disentangle gene expression associated with $\mathrm{E}_{2}$ and $\mathrm{P}_{4}$. Still, there are some 
differences. For example, the "oestrogen up-regulated" gene set (Frasor/KEGG) was only significant for $E_{2}$, and although the total "oestrogen regulated" gene set (Frasor/KEGG) was significant for both $\mathrm{E}_{2}$ and $\mathrm{P}_{4}$, there was no overlap between the core genes up-regulated in the high group. In general, we found a much larger overlap of core genes up-regulated in the low than in the high group for the gene sets that were significant for both hormones.

The " $E_{2}$ or $E_{2} / P$ systemic" gene set turned out to be a more reliable oestrogen signature than the " $E_{2}$ alone" gene set, probably because of the inclusion of oral highdose $E_{2}$ users $(n=7)$ and/or the generally larger group of users in the " $E_{2}$ or $E_{2} / P$ systemic" category. Interestingly, as opposed to most of the other significant gene sets, the majority of the genes in this gene set were upregulated in the high $\mathrm{E}_{2}$ group. There was a high, although not complete, concordance in the direction of gene expression between endogenous and exogenous $E_{2}$ for this gene set. Opposing directions for some genes may have been due to the progestogen content in several of the products in this HT category, or possibly differential feedback mechanisms between endogenous and exogenous hormones. Further research may reveal the functions and regulation of these core genes.

In addition to the core genes, interesting single genes in the " $E_{2}$ or $E_{2} / P$ systemic" gene set included PNRC2, a coactivator of nuclear receptors such as the ESRRs (oestrogen related receptors), and CSMD2, which has been previously found to be differentially expressed in HT users [15]. Among the remaining genes aspiring to, but not quite reaching, core gene status (Figure 4), are also VPS37A (no. 8), RNF139 (No. 9) and CNOT7 (No. 12), indicating that these overlapping genes from Figure 2 are worthy of further research into their association with sex hormones. Noteworthy in the " $E_{2}$ alone" gene set is the TSC22D1 gene, whose protein product may play a role in resistance toward Tamoxifen ${ }^{\circledR}$ treatment in breast cancer patients[34]

The tibolone and thyroxine gene sets did not meet our significance criteria for any of the hormones. One might have expected some association with FSH, but the number of users in these two categories was probably too small to generate reliably specific expression sets.

None of the gene sets were differentially expressed between high and low levels of FSH, SHBG or T. Compared with the wide variety of target tissues and the acknowledged effects of steroid hormones, FSH and SHBG would be expected to have a more limited association with gene expression. The biological effect of FSH is essentially the stimulation of gonadal $E_{2}$ and $P_{4}$ synthesis, and in postmenopausal women FSH has lost its gonadotropic potency. Although it has been suggested that SHBG possesses some signalling properties
[35], it is mainly a transport protein. Adding the moderate variation in FSH and SHBG levels across the study population, a difference in gene expression might be difficult to detect. Testosterone is not a major hormone in women. Although it is a potent steroid, the differences in gene expression relative to low levels of $\mathrm{T}$ are probably not detectable in a setting with high background variability.

Seven gene sets related to immune responses or cells active in the immune system were differentially expressed between the high and low $\mathrm{E}_{2}$ concentration groups. Additionally, two gene sets associated with exercise (stress response and inflammatory response) and the proto-oncogene gene set could be viewed as immune system related. Sex hormones have been found to influence the immune system through steroid receptors in white blood cells [36]. In general, female sex hormones are viewed as suppressors of the immune response. It has been shown that plasma levels of both interleukin 6 (IL6) and interleukin 2 (IL2) increase after menopause (i.e., with decreasing levels of $E_{2}$ ) and that HT opposes this effect [36]. Although neither IL6 nor IL2 were among the 16185 probes in our data set, the higher expression of the respective receptors, $I L 6 R$ and $I L 2 R$, at low $\mathrm{E}_{2}$ concentrations indicates the suppressive effects of $E_{2}$. Other interesting core genes include the heat shock proteins (HSPs) in the "stress response from exercise" gene set. The HSPs function as intracellular chaperones for other proteins (integrity and folding), and some have been found to play a role in the rapid non-genomic effects of steroid hormones [37], which is interesting in light of the rapid responses seen in these genes following exercise [38]. FOS is a high-influence core gene for both $\mathrm{E}_{2}$ and $\mathrm{P}_{4}$. In fact, all of the FOS-containing gene sets were differentially expressed. However, contradictory to Frasor et.al. [39], FOS was up-regulated in the low $E_{2}$ group, together with EPB41L3 and AP1G1. By contrast, CXCL12, the steroid 21-hydroxylase $C Y P 21 A 2$ and PDZK1 were congruously up-regulated in the high- $\mathrm{E}_{2}$ group. According to Kendall et al. [20], FOS is up-regulated by oestrogen deprivation, which supports our results, while SGK3 and TAGLN are down-regulated, which contradicts our results. These contradictions in gene expression direction may arise from methodological differences or from regulatory and feed-back mechanisms similar to the above mentioned discordance for the " $E_{2}$ or $E_{2} / P$ systemic" gene set.

Though the differential expression of the tibolone gene set lacked statistical significance, the network mapping suggested that further research is warranted. Interesting single genes included COMT, a central enzyme in the metabolism of oestrogens; and SOAT1, an intracellular protein that forms cholesterol esters from cholesterol, thereby possibly contributing to 
atherosclerotic plaques. SOAT1 was up-regulated among tibolone users, in accord with the known increased risk of stroke associated with tibolone use [40]. A larger data set would contain a larger group of tibolone users and provide a more solid basis for finding tibolone associated genes.

\section{Strengths and limitations}

The NOWAC study subjects were randomly drawn from the Central Population Register and are representative of the population in which future microarray based diagnostic and/or prognostic tests for breast cancer will be applied. Our ability to detect subtle effects in a dataset with a high degree of random variation is reassuring.

Among the limitations of this study is the lack of information regarding the relative proportions of peripheral blood cell types. If differences in hormone concentrations or HT use are associated with the numbers of particular type(s) of peripheral blood cells, it may have influenced our results. Research into the influence of sex hormones on leukocyte cell count reveals conflicting results [36]. Although the women were healthy enough to visit a physician's office, we had limited information regarding disease and immune system status beyond what could be inferred from the self-reported drug use. However, a systematic difference in disease prevalence between hormone concentration levels is unlikely.

Our FDR cut-off of $<0.25$ may have exceeded conventional limits, whereas FDR $\leq 0.10$ is considered acceptable [41]. A higher FDR can be accepted, however, at least when analysing gene sets extracted from previous publications and thereby supported by research. Also, we were not looking for single genes in the gene-wise analyses but for groups of genes that may have explained known effects. For example, among the 33 genes in the " $E_{2}$ or $E_{2} / P$ systemic" gene set, 9 had $F D R \leq 0.10$, but only two of these genes were among the core genes differentially expressed between the high and low $\mathrm{E}_{2}$ group. Hence, if we had used the $\leq 0.10 \mathrm{FDR}$ cut-off we might have overlooked this oestrogen signature.

Our results are based on a snapshot measurement; we have only one blood sample from each woman and can infer nothing about intra-individual variation or variation over time. However, previous reports have shown low intra-individual variation in gene expression compared with inter-individual variation $[42,43]$.

The study design prevented an extensively standardised blood sampling protocol with regards to fasting, blood sample handling and transport, etc. However, the main source of technical variation in this data set was associated with the performance of the assay and not with pre-analytical processing[25].

The gene set enrichment analyses were adjusted for age and/or BMI. We found no significant differences between the compared categories with respect to fasting and smoking. However, residual confounding may have influenced the differences found between high and low concentrations of $\mathrm{E}_{2}$ and $\mathrm{P}_{4}$.

Differentially expressed genes have not been validated using an independent data set, and our results should be interpreted accordingly.

\section{Conclusions}

Through exploring potential associations between sex hormones and gene expression, we have identified a novel oestrogen gene expression signature, and further research may reveal the function of these genes in relation to $E_{2}$. A potential tibolone signature was also defined that warrants further research. Several gene sets, particularly those oestrogen and immune system related but also gene sets related to drug metabolism, exercise and carbohydrate/protein ingestion, were differentially expressed between high and low levels of $\mathrm{E}_{2}$ and $\mathrm{P}_{4}$.

\section{Additional material}

Additional file 1: Questionnaire, translated from Norwegian. This is a
PDF-file of the questionnaire that the women completed at the time of
the blood draw.
Additional file 2: Gene sets included in the gene set enrichment
analysis. This is a Word table showing all the 56 gene sets included in
the analysis. The gene sets are categorised as related to female sex
hormone or menopause, as related to blood cells and the immune
system, or, as related to other factors.
Additional file 3: Gene sets differentially expressed between high
and low hormone concentrations, age adjusted with HT and
thyroxin users excluded. This is a Word table showing which of the 56
gene sets that showed a statistically significant differential expression
between the women with high and low plasma concentrations of
estradiol and progesterone.

\section{Acknowledgements}

The study was supported by The Research Council of Norway, the University of Troms $\varnothing$ and the European Research Council. We gratefully acknowledge the assistance of Yngve Figenschau, Department of Medical Biochemistry, University Hospital of North Norway, in conducting the plasma hormone measurements, and Bente Augdal and Merete Albertsen for administrating the data collection.

\section{Author details}

'Department of Community Medicine, University of Troms $\varnothing$, Troms $\varnothing$, Norway. ${ }^{2}$ Norwegian Institute for Air Research, Tromsø, Norway.

\section{Authors' contributions}

$M W, V D$ and EL participated in designing the study. MW performed the statistical analyses and drafted the manuscript. KSO executed the laboratory microarray analyses. CR and VD assisted in statistical analyses and the drafting of the manuscript. EL is the principal investigator of the NOWAC study. All authors read and approved the final manuscript.

\section{Competing interests}

The authors declare that they have no competing interests.

Received: 18 June 2010 Accepted: 31 March 2011

Published: 31 March 2011 
References

1. Key TJ, Appleby P, Barnes I, Reeves G: (The Endogenous Hormones and Breast Cancer Collaborative Group) Endogenous Sex Hormones and Breast Cancer in Postmenopausal Women: Reanalysis of Nine Prospective Studies. J Natl Cancer Inst 2002, 94:606-616.

2. Missmer SA, Eliassen AH, Barbieri RL, Hankinson SE: Endogenous Estrogen, Androgen, and Progesterone Concentrations and Breast Cancer Risk Among Postmenopausal Women. J Natl Cancer Inst 2004, 96:1856-1865.

3. Kaaks R, Rinaldi S, Key TJ, Berrino F, Peeters PHM, Biessy C, Dossus L, Lukanova A, Bingham S, Khaw KT, et al: Postmenopausal serum androgens, oestrogens and breast cancer risk: the European prospective investigation into cancer and nutrition. Endocr Relat Cancer 2005, 12:1071-1082

4. Writing Group for the Women's Health Initiative: Risks and Benefits of Estrogen Plus Progestin in Healthy Postmenopausal Women: Principal Results From the Women's Health Initiative Randomized Controlled Trial. JAMA 2002, 288:321-333.

5. Million Women Study Collaborators: Breast cancer and hormonereplacement therapy in the Million Women Study. The Lancet 2003, 362:419-427.

6. Bakken $\mathrm{K}$, Alsaker E, Eggen AE, Lund E: Hormone replacement therapy and incidence of hormone-dependent cancers in the Norwegian Women and Cancer study. Int J Cancer 2004, 112:130-134.

7. Waaseth M, Bakken K, Dumeaux V, Olsen K, Rylander C, Figenschau Y, Lund $\mathrm{E}:$ Hormone replacement therapy use and plasma levels of sex hormones in the Norwegian Women and Cancer Postgenome Cohort - a cross-sectional analysis. BMC Women's Health 2008, 8:1.

8. Castelo-Branco C, de Osaba MJM, Fortuny A, Iglesias X, Gonzalez-Merlo J: Circulating Hormone Levels in Menopausal Women Receiving Different Hormone Replacement Therapy Regimens. J Reprod Med 1995, 40:556-560.

9. Casson PR, Elkind-Hirsch KE, Buster JE, Hornsby PJ, Carson SA, Snabes MC: Effect of Postmenopausal Estrogen Replacement on Circulating Androgens. Obstetrics \& Gynecology 1997, 90:995-998.

10. Hofling M, Carlström K, Svane G, Azavedo E, Kloosterboer H, Schoultz BV Different effects of tibolone and continuous combined estrogen plus progestogen hormone therapy on sex hormone binding globulin and free testosterone levels - an association with mammographic density. Gynecol Endocrinol 2005, 20:110-115.

11. Dören M, Rübig A, Coelingh Bennink HJT, Holzgreve W: Differential effects on the androgen status of postmenopausal women treated with tibolone and continuous combined estradiol and norethindrone acetate replacement therapy. Fertil Steril 2001, 75:554-559.

12. Liew CC, Ma J, Tang HC, Zheng R, Dempsey AA: The peripheral blood transcriptome dynamically reflects system wide biology: a potential diagnostic tool. Journal of Laboratory and Clinical Medicine 2006, 147:126-132.

13. Mohr S, Liew CC: The peripheral-blood transcriptome: new insights into disease and risk assessment. Trends in Molecular Medicine 2007, 13.422-432.

14. Chatterjee SK, Zetter BR: Cancer biomarkers: knowing the present and predicting the future. Future Oncology 2005, 1:37-50.

15. Dumeaux V, Johansen J, Borresen-Dale AL, Lund E: Gene expression profiling of whole-blood samples from women exposed to hormone replacement therapy. Mol Cancer Ther 2006, 5:868-876.

16. Dumeaux $V$, Lund $E$, Børresen-Dale AL: Comparison of globin RNA processing methods for genome-wide transcriptome analysis from whole blood. Biomarkers Med 2008, 2:11-21.

17. Dvornyk V, Liu Y, Lu Y, Shen H, Lappe JM, Recker RR, Deng H, Lei S: Effect of Menopause on Gene Expression Profiles of Circulating Monocytes: A Pilot in vivo Microarray Study. Journal of Genetics and Genomics 2007. 34:974-983.

18. Xiao $P$, Chen $Y$, Jiang $H$, Liu YZ, Pan F, Yang TL, Tang ZH, Larsen JA, Lappe JM, Recker RR, Deng Hw: In vivo genome-wide expression study on human circulating B cells suggests a novel ESR1 and MAPK3 network for postmenopausal osteoporosis. Journal of Bone and Mineral Research 2008, 23:644-654.

19. Pollanen E, Ha Ronkainen P, Suominen H, Takala T, Koskinen S, Puolakka J, Sipila S, Kovanen V: Muscular Transcriptome in Postmenopausal Women With or Without Hormone Replacement. Rejuvenation Research 2007 10:485-500E
20. Kendall A, Anderson H, Dunbier AK, Mackay A, Dexter T, Urruticoechea A, Harper-Wynne C, Dowsett M: Impact of Estrogen Deprivation on Gene Expression Profiles of Normal Postmenopausal Breast Tissue In vivo. Cancer Epidemiol Biomarkers Prev 2008, 17:855-863.

21. Frasor J, Danes JM, Komm B, Chang KCN, Lyttle CR, Katzenellenbogen BS: Profiling of Estrogen Up- and Down-Regulated Gene Expression in Human Breast Cancer Cells: Insights into Gene Networks and Pathways Underlying Estrogenic Control of Proliferation and Cell Phenotype. Endocrinology 2003, 144:4562-4574.

22. Ji Q, Liu Pl, Chen PK, Aoyama C: Follicle stimulating hormone-induced growth promotion and gene expression profiles on ovarian surface epithelial cells. International Journal of Cancer 2004, 112:803-814

23. Dumeaux V, Borresen-Dale AL, Frantzen JO, Kumle M, Kristensen V, Lund E: Gene expression analyses in breast cancer epidemiology: the Norwegian Women and Cancer postgenome cohort study. Breast Cancer Research 2008, 10:R13.

24. Lund E, Dumeaux V, Braaten T, Hjartaker A, Engeset D, Skeie G, Kumle M: Cohort Profile: The Norwegian Women and Cancer Study - NOWAC Kvinner og kreft. Int J Epidemiol 2008, 37:36-41.

25. Dumeaux V, Olsen KS, Nuel G, Paulssen RH, Børresen-Dale AL, Lund E: Deciphering Normal Blood Gene Expression Variation - The NOWAC Postgenome Study. PLoS Genet 2010, 6:e1000873.

26. Smyth GK: Linear Models and Empirical Bayes Methods for Assessing Differential Expression in Microarray Experiments. Stat App/ Genet Mol Biol 2004, 3, Article 3.

27. Benjamini $Y$, Hochberg Y: Controlling the False Discovery Rate: A Practical and Powerful Approach to Multiple Testing. J R Stat Soc Series B Stat Methodol 1995, 57:289-300

28. Kanehisa M, Goto S: KEGG: Kyoto Encyclopedia of Genes and Genomes. Nucl Acids Res 2000, 28:27-30

29. Carbon S, Ireland A, Mungall CJ, Shu S, Marshall B, Lewis S, the AmiGO Hub, the Web Presence Working Group: AmiGO: online access to ontology and annotation data. Bioinformatics 2009, 25:288-289.

30. Goeman JJ, van de Geer SA, de Kort F, van Houwelingen HC: A global test for groups of genes: testing association with a clinical outcome. Bioinformatics 2004, 20:93-99.

31. Safran M, Solomon I, Shmueli O, Lapidot M, Shen-Orr S, Adato A, BenDor U, Esterman N, Rosen N, Peter I, et al: GeneCardsTM 2002: towards a complete, object-oriented, human gene compendium. Bioinformatics 2002, 18:1542-1543.

32. Huang DW, Sherman BT, Lempicki RA: Systematic and integrative analysis of large gene lists using DAVID bioinformatics resources. Nat Protocols 2008, 4:44-57.

33. Huttenhower C, Haley EM, Hibbs MA, Dumeaux V, Barrett DR, Coller HA Troyanskaya OG: Exploring the human genome with functional maps. Genome Res 2009, 19:1093-1106.

34. Meijer D, Jansen M, Look M, Ruigrok-Ritstier K, van Staveren I, Sieuwerts A, van Agthoven T, Foekens J, Dorssers L, Berns E: TSC22D1 and PSAP predict clinical outcome of tamoxifen treatment in patients with recurrent breast cancer. Breast Cancer Research and Treatment 2009, 113:253-260.

35. Fortunati N, Catalano MG: Sex Hormone-binding Globulin (SHBG) and Estradiol Cross-talk in Breast Cancer Cells. Horm Metab Res 2006 38:236-240.

36. Bouman A, Heineman MJ, Faas MM: Sex hormones and the immune response in humans. Hum Reprod Update 2005, 11:411-423.

37. Simoncini T, Genazzani A: Non-genomic actions of sex steroid hormones. Eur J Endocrinol 2003, 148:281-292.

38. Connolly PH, Caiozzo VJ, Zaldivar F, Nemet D, Larson J, Hung Sp, Heck JD, Hatfield GW, Cooper DM: Effects of exercise on gene expression in human peripheral blood mononuclear cells. J App/ Physiol 2004, 97:1461-1469.

39. Frasor J, Stossi F, Danes JM, Komm B, Lyttle CR, Katzenellenbogen BS: Selective Estrogen Receptor Modulators: Discrimination of Agonistic versus Antagonistic Activities by Gene Expression Profiling in Breast Cancer Cells. Cancer Res 2004, 64:1522-1533.

40. Kenemans P: Tibolone revisited: still a good treatment option for healthy, early postmenopausal women. Gynecological Endocrinology 2010, 26:237-239.

41. Breitling R: Biological microarray interpretation: The rules of engagement. Biochimica et Biophysica Acta (BBA) - Gene Structure and Expression 2006, 1759:319-327. 
42. Cobb JP, Mindrinos MN, Miller-Graziano C, Calvano SE, Baker HV, Xiao W Laudanski K, Brownstein BH, Elson CM, Hayden DL, et al: Application of genome-wide expression analysis to human health and disease. Proc Natl Acad Sci USA 2005, 102:4801-4806.

43. van Erk MJ, Blom WA, van Ommen B, Hendriks HF: High-protein and highcarbohydrate breakfasts differentially change the transcriptome of human blood cells. Am J Clin Nutr 2006, 84:1233-1241.

Pre-publication history

The pre-publication history for this paper can be accessed here: http://www.biomedcentral.com/1755-8794/4/29/prepub

doi:10.1186/1755-8794-4-29

Cite this article as: Waaseth et al:: Sex hormones and gene expression

signatures in peripheral blood from postmenopausal women - the NOWAC postgenome study. BMC Medical Genomics 2011 4:29.

\section{Submit your next manuscript to BioMed Central} and take full advantage of:

- Convenient online submission

- Thorough peer review

- No space constraints or color figure charges

- Immediate publication on acceptance

- Inclusion in PubMed, CAS, Scopus and Google Scholar

- Research which is freely available for redistribution

Submit your manuscript at www.biomedcentral.com/submit 